\title{
Opinion
}

\section{Gene Editing and The Future of Humanity How Far Is Too Far?}

\author{
George Zhuang* \\ Department of History, University of Florida, USA
}

*Corresponding author: George Zhuang, Department of History, University of Florida, USA.

Received Date: June 30, 2019

Published Date: July 01, 2019

\section{Opinion}

Clustered regularly interspaced short palindromic repeats (CRISPR for short) technology has been much talked about in the scientific community for many years now. It is, very basically, "[a] technology that facilitates making specific changes in the DNA of humans, other animals, and plants [1]." First discovered by Francisco Mojica in 1993 and later identified by the same, as part of an adaptive immune system, CRISPR has since been developed further. Much further. In 2010, CRISPR was first used to cleave target DNA, demonstrating its usefulness for genetic edits on specific DNA targets [2]. Since then, the use of CRISPR has exploded within the scientific community, opening up a vast number of possibilities for researchers as well as new lines of research in areas of study ranging from medicine to food production, in addition to genetics (Figure).

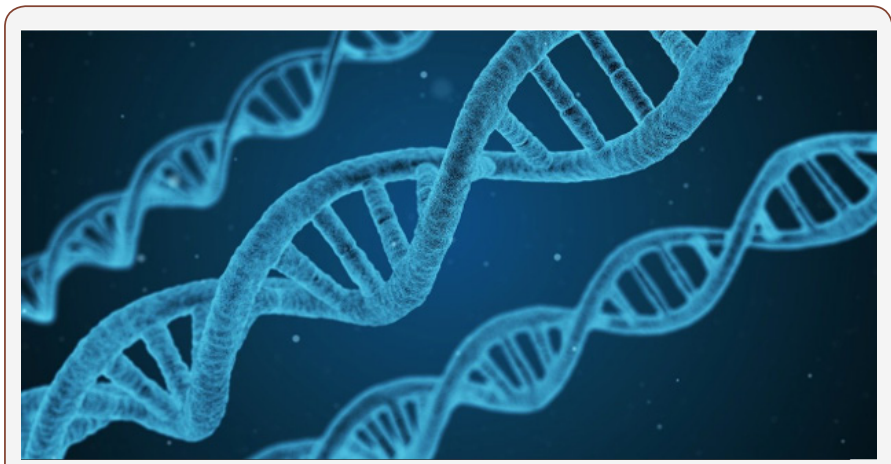

Figure 1: CRISPR technology allows scientists and researchers to directly edit an organism's genetic code.

However, CRISPR may not be the only way forward. Researchers are continuously finding better, more efficient, and safer ways to edit genes. CRISPR, in its heyday, has been compared to a pair of genetic scissors, able to precisely snip faulty genes out of genetic code (DNA). However, "At a recent medical conference, scientist and Harvard professor George Church presented an argument causing anxiety among healthcare investors: The days of CRISPR gene editing might be numbered. He called CRISPR a 'blunt ax' and said 'it's called editing, I think it's really genome vandalism."'

"In multiple recent speaking engagements, Church laid out four different gene editing systems that may move the field "beyond cutting" for applications as diverse as industrial biotechnology, human medicine, and xenotransplantation, which is the process of grafting or transplanting organs or tissues between members of different species." These four gene editing systems he mentioned, according to The Motley Fool, were: lambda-red recombinase, phase integrases, TAL deaminases, and chemical targeting [3].

In any case, twin girls, named Lulu and Nana, were born with CRISPR-edited genes in November 2018, the first humans born with their genes intentionally edited [4]. One of the researchers responsible, He Jiankui, a researcher at the Southern University of Science and Technology in Shenzhen, utilized CRISPR gene editing technology to change the twins' genetic code by removing the CCR5 gene from the girls' DNA, effectively making them HIV-resistant. Now, CRISPR has long proven its value in the medical community. In fact, Feng Zhang, in an interview with CBS correspondent Bill Whitaker, mentions that there are "about 6,000 or more diseases that are caused by faulty genes," which Zhang hopes can be addressed with CRISPR technology [5].

The fact that researchers were able to genetically edit out the gateway for disease-causing pathogens is not particularly surprising. The significance of the story of He Jiankui and his 'test tube babies' is this: according to new research, reported on by RT, the CCR5 genes that He Jiankui took the liberty of removing from the girls not only made the babies resistant to HIV, but also may, "have [given them] mental 'superpowers'. The same modification performed on the girls' DNA - significantly improves cognition, learning, and memory in mice and men [6]." However, the CCR5 
removal may come with a downside as well." Even if editing worked perfectly, people without normal CCR5 genes face higher risks of infection by other viruses such as West Nile, and of dying from the flu," according to Kiran Musunuru, a University of Pennsylvania gene editing expert [4]."

However, that these twins were able to be born HIV-resistant at all, due to a genetic edit, cannot be understated. When you also consider that these girls may, as a product of the CCR5 generemoval, have higher levels of cognition than the average person, we must then consider the problems as well as the potential benefits of such a genetic alteration. True, this experiment opens a slew of possibilities for further enhancement of the human race, but this type of development may also have an incalculable number of risks and innumerable unintended and possibly catastrophic consequences. And I don't just mean we'll become more susceptibility to West Nile and the flu.

Consider the movie, I Am Legend. In this film, based on a novel of the same name by Richard Matheson, "Dr. Krippen (Emma Thompson) is interviewed on TV about her great discovery: she has changed the measles virus genetically so that it attacks cancerous cells. She explains that all the cancer patients which her cure has been tested on have recovered so far. The scene jumps to three years later. We see New York City has become an empty and desolate place, devoid of human life." The cure for cancer that Dr. Krippen developed had unintentionally mutated with disastrous consequences [7]. Of course, as it is a work of fiction that has little to do with genetic enhancement, this is a relatively weak example. But the idea remains the same. Human genetic enhancement is a great way (and may be the only way in the future) to move humanity forward on an evolutionary scale. Similarly, improvements in human genome mapping can lead to better and more personalized 'gene therapies' that could be used to treat many of the "6,000 or more diseases ... caused by faulty genes" that researcher Feng Zhang mentioned [8-10].

Whatever the route gene therapy takes, whether the most success is found in CRISPR or in 'lambda-red recombinase', we must proceed with extreme caution, in ways that are socially, economically, and medically responsible.

\section{Acknowledgement}

None.

\section{Conflict of Interest}

No conflict of interest.

\section{References}

1. http://sitn.hms.harvard.edu/flash/2014/crispr-a-game-changinggenetic-engineering-technique/

2. https://www.broadinstitute.org/what-broad/areas-focus/projectspotlight/crispr-timeline

3. https://www.fool.com/investing/2019/01/18/4-gene-editingtechnologies-that-could-replace-cri.aspx

4. https://www.indiatoday.in/science/story/first-genetically-modifiedbabies-china-he-jiankui-1396429-2...

5. https://www.cbsnews.com/news/crispr-the-gene-editing-toolrevolutionizing-biomedical-research/

6. https://www.rt.com/news/452130-crispr-babies-china-intelligence/

7. https://www.imdb.com/title/tt0480249/

8. https://www.livescience.com/58790-crispr-explained.html

9. h t t p s : / / w w w. n p r. org/s e c t i o n s/ h e a l t h shots/2014/06/26/325213397/a-crispr-way-to-fix-faulty-genes

10. https://www.sciencemag.org/topic/crispr 